\title{
A importância da independência editorial na credibilidade e no reconhecimento de uma revista científica
}

\author{
The importance of editorial independence for the credibility of a scientific journal
}

\author{
Jefferson Pedro Piva*
}

\begin{abstract}
Mais de 20.000 revistas médicas são editadas no planeta, e todas almejando o mesmo objetivo: reconhecimento e credibilidade. Uma excelente reputação despertará um maior interesse entre os leitores e uma acirrada disputa entre os pesquisadores para veicular suas pesquisas nesta revista, assim como gerará, também, um grande aporte financeiro de patrocinadores e assinantes. The New England Journal of Medicine é uma destas revistas médicas que detém um elevadíssimo índice de impacto, e também um pleno êxito financeiro. Em 1998 obteve um investimento de publicidade e assinantes superior a 70 milhões de dólares ${ }^{1}$. Um outro periódico com a mesma reputação e sucesso é The Journal of the American Medical Association. Apesar de todo este sucesso, estes dois periódicos tiveram seus editores destituídos no ano de 1999 em razão de divergências e conflitos de interesses com os respectivos proprietários ou entidades mantenedoras. Os prejuízos foram imediatos, pois tanto leitores quanto pesquisadores suspeitaram estar ocorrendo uma quebra na isenção e na credibilidade destes periódicos ${ }^{1,2}$. Estas reações e conseqüências somente foram revertidas após um transparente processo seletivo, realizado por comissões isentas e independentes, para preencher o cargo de editor das respectivas revistas.
\end{abstract}

$\mathrm{Na}$ maior parte das vezes os interesses dos editores de revistas médicas são sinérgicos e convergentes com os interesses das respectivas sociedades mantenedoras. Entretanto, em determinadas circunstâncias estes interesses podem ser competitivos ou conflitantes. Nestes episódios

\footnotetext{
* Editor (1994-2002), Jornal de Pediatria.
}

constatou-se que até mesmo sólidas e respeitadas revistas médicas estão sujeitas a abalos em sua credibilidade e reputação. Ficou evidente a necessidade de criar mecanismos protetores e reguladores da função do editor. Ficou claro, também, que o editor e seu corpo editorial não desempenham uma função apenas burocrática, pois seu desempenho influi diretamente nos destinos (respeitabilidade) das revistas médicas.

Questionava-se, a partir daí, em uma ampla e pública discussão: até onde deve ir a submissão ou a independência dos editores para com as respectivas entidades? Qual o limite "aceitável" de interferência que diretores de sociedades ou proprietários de revistas poderiam exercer sobre os respectivos editores? ${ }^{1}$

Para melhor analisar este tema é interessante que se discuta qual o caminho percorrido para que alguém chegue a ser empossado no cargo de editor de uma revista médica. Na imensa maioria das vezes sua indicação ou seleção está baseada em suas reconhecidas habilidades assistenciais ou como pesquisador. Porém, poucos têm uma carreira afirmada dentro deste cenário ${ }^{3}$. Em um estudo envolvendo 190 editores das mais conceituadas revistas médicas do planeta observou-se que $30 \%$ foram eleitos juntamente com a diretoria da respectiva sociedade, $25 \%$ indicados pelo editor anterior e, apenas, $18 \%$ foram selecionados através de concurso ou por uma comissão independente ${ }^{4}$. Evidentemente todos aqueles não selecionados de forma independente poderiam ter sua isenção na defesa dos interesses editoriais questionada.

Há oito anos decidimos, juntamente com a Diretoria da Sociedade Brasileira de Pediatria, assumir o compromisso público para que o Jornal de Pediatria viesse a resgatar e 
consolidar a posição de melhor revista pediátrica de nosso país. Pretendíamos conquistar esta posição através de um trabalho que privilegiasse a revisão dos processos visando a atender prioritariamente aos interesses de nossos clientes (leitores, pesquisadores, centros de pesquisa e anunciantes) $)^{5}$.

Foram implementadas inúmeras mudanças, tais como reorganização da secretaria, rígido controle do fluxo de artigos, adoção dos mesmos padrões internacionais utilizados nas mais renomadas revistas para revisar artigos científicos, reuniões quinzenais do conselho editorial, fixação de prazos para todas as etapas do processo, lançamento da versão eletrônica da revista, entre outras.

Estas reformas estruturais, aliadas ao crescimento dos cursos de pós-graduação em pediatria no Brasil, permitiram que o Jornal de Pediatria obtivesse um amplo reconhecimento, sendo considerada como uma das melhores revistas médicas de nosso país. O fluxo de submissão de artigos tem crescido constantemente (aumento da competitividade) e como consequiência um aumento também, na taxa de recusa (ao redor de $45 \%$ ). Para que se tenha uma idéia de seu poder de penetração (impacto da divulgação), a média de acessos mensais ao site www.jped.com.br tem oscilado entre 9.000 e 15.000 (300 a 500 acessos diários). Como resultado, obtivemos diferentes e distinguidas formas de reconhecimento. Estamos hoje incluídos na base de dados da Excerpta, da Embase, da Lilacs, e do SciELO, além de recebermos reconhecimento da CAPES, do CNPq e da quase totalidade dos cursos de pós-graduação em pediatria.

Dentre todos estes, elegeria como o fato emblemático da nova etapa do Jornal de Pediatria o momento da troca de editor de nossa revista. Neste ato se consolida a última etapa desta reforma estrutural. O editor para os próximos 4 anos foi selecionado através de concurso aberto, amplamente divulgado e coordenado por uma comissão independente, especificamente designada para este fim. $\mathrm{O}$ espectro da atividade de editor do Jornal de Pediatria está consolidada nos estatutos da SBP e normatizada em regimento próprio, onde se estabelecem suas obrigações e deveres de forma a assegurar e limitar sua "independência editorial".

Dentro deste cenário, o Prof. Dr. Renato Procianoy foi selecionado como o novo editor do Jornal de Pediatria para os próximos 4 anos. Trata-se de um colega com relevantes serviços prestados à nossa Sociedade, com uma carreira universitária coroada de sucesso e que participou de todo este processo organizacional de nossa revista, desde seus primórdios. Por isso mesmo, o Prof. Procianoy, além de comprometido com o passado, é avalista do futuro do Jornal de Pediatria. Sou testemunha de sua capacidade profissional; portanto, não tenho dúvida alguma de que nossa revista tem assegurado um futuro extremamente promissor. Desejo a ele a mesma sorte que tive de contar com a qualidade, o entusiasmo e a dedicação de colaboradores do "calibre" de José M. Lopes, Alzira Lobo, Clemax Santana, Flávio Sztajnbok, Danilo Blank, Sérgio Amantéa, Elsa Giugliani, Ricardo Feijó, Magda Nunes, Pedro Celiny e Renato Procianoy, que tornaram a função de editor extremamente facilitada e prazerosa.

\section{Referências bibliográficas}

1. Rennie D. Editors and owners - stretching reputation too far. JAMA 1999; 282:783-4.

2. Mitka M. NEJM Editor Jerome Kassirer, MD, loses post over "administrative issues". JAMA 1999; 282:622-3.

3. Kassirer J. Why be a medical editor? JAMA 2001; 285:2253.

4. The reported training and experience of editors in chief of specialist clinical medical journals. JAMA 1998; 280:286-7.

5. Piva JP. O crescimento através da qualidade. J Pediatr (Rio J) 1994; 70:71-2. 